\title{
Organizaciones vecinales: EL BARRIO COMO FUENTE DE IDENTIDAD POLÍTICA ${ }^{1}$
}

\author{
José Miguel Candia \\ Candidato a doctor en Estudios Latinoamericanos por la Facultad \\ de Ciencias Políticas y Sociales de la UNAM \\ E-mails: jcandiall@ hotmail.com; jcandia@prodigy.net.mx
}

\section{Resumo}

El artículo quiere poner en tela de juicio la debilidad de los movimientos sociales de barrios ante el proceso de globalización económica en los términos del liberalismo. Se quiere demostrar que los movimientos de barrio, por el carácter localizado y particularizado de su emergencia y alcance no logran imprimir cambios significativos que puedan tratar de quitar fuerza a los procesos de transformaciones en curso.

Palabras clave: movimientos sociales de barrios; globalización y liberalismo.

as políticas neoliberales de modernización capitalista modificaron radicalmente el universo social de nuestros países. Se incrementó el contingente de población desempleada, subocupada y de trabajadores precarios, y aumentó la pobreza además de caer el empleo en el sector industrial. Al mismo tiempo, se expandieron las relaciones de trabajo regidas por contratos flexibles que hacen más inestable la vinculación laboral y desprotegen a quienes prestan sus servicios bajo estas condiciones.

Es necesario apuntar que otros efectos relevantes de estas políticas fueron la reducción de la cobertura de las instituciones de

\footnotetext{
' Ponencia presentad al XXIII Congreso de la ALAS, del 29 de octubre al 2 de noviembre de 2001, Ciudad Antigua, Guatemala..
} 
seguridad social y la amputación de un segmento importante de la antigua industria nacional, que se reconvirtió en plantas maquiladoras o mutó en oficinas gestoras de importaciones. También se cancelaron los subsidios y créditos sobre los cuales se instrumentaron amplias políticas de estímulo a los productores locales e hicieron posible que durante los treinta años posteriores a la segunda guerra - se otorgara un generoso apoyo al consumo popular.

Parece acertada la definición de algunos investigadores cuando dicen que la situación social de América Latina es un escándalo (O’DONNELL, 1999). A mediados de los años 90, el $46 \%$ de los habitantes de la región vivía en la pobreza y casi la mitad de ellos eran indigentes carentes de los más elementales recursos para atender necesidades fundamentales. El número de pobres era, a finales del siglo que acabamos de dejar atrás, mayor que a comienzos de la década de los 70. Para 1995 se estimaban 200 millones de pobres, 80 millones más que los registrados en 1970. La cifra, por si sola apabullante, incluye 95 millones de indigentes, 30 millones más que los identificados hace 30 años (O'DONNELL, 1999). No obstante, el problema no se agota en el conteo de pobres ni en la expresión de asombro que esas cifras pueden provocar. Existe otro indicador social igualmente aterrador, se trata del aumento de la desigualdad: los ricos son ahora más ricos y el incremento de la cantidad de familias "carenciadas" - de acuerdo al eufemismo que adoptaron algunos gobiernos para dirigirse a los grupos que viven en condiciones de pobreza extrema - parece estar fuera del control de las políticas públicas.

La situación que se describe incluye a todas las naciones del área. Algunos países que habían sido excepciones parciales a la regla en particular los casos de Argentina y Chile - incrementaron notoriamente la pobreza y la desigualdad. Apenas Uruguay y Costa Rica mantuvieron, parcialmente, las condiciones previas a la catástrofe de los 80. Puede apuntarse una experiencia, extraña y solitaria, de mejoría relativa, se trata de Colombia, que logró aminorar la brecha de desigualdad social y pobreza pero partiendo de niveles de marginalidad más altos que los registrados en los países que se mencionan anteriormente. Si se analiza la cuestión social a partir de la lectura de otros indicadores como mortalidad infantil, esperanza de vida $y$ alfabetización el panorama es algo más alentador, sin embargo, en los 
últimos 30 años el acceso de las familias pobres a los servicios sociales cmpcoraron. De las naciones que iniciaron de manera más temprana la construcción institucional que los sociólogos y políticos europeos llamaron "Estado de Bienestar", únicamente Uruguay logró escapar a este proceso de decadencia generalizada (SOJO, 1999)

Los efectos de las políticas de reestructuración capitalista sobre el mundo del trabajo han sido particularmente significativos. Un primer fenómeno, de fácil identificación sin necesidad de recurrir a una indagación estadística detallada, es la generalización de formas atípicas de empleo y la degradación de las condiciones laborales. La vastísima producción bibliográfica que se ha dedicado al estudio del tema coincide en agrupar este tipo de actividades laborales bajo la conceptualización común de "precariedad ocupacional". No es propósito de este artículo hacer un recuento minucioso del proceso de precarización de las condiciones de trabajo por lo que sólo se mencionarán algunos de los rasgos que lo definen. De las transformaciones registradas en el mercado laboral, hay cinco elementos que por su relevancia, constituyen indicadores sustantivos de la desestructuración de las relaciones de trabajo, por lo que es necesario referir de manera puntual, a cada uno de ellos:

1. La fuerte expansión del autoempleo o trabajo por cuenta propia;

2. La caída relativa del trabajo asalariado en las actividades industriales y el incremento de la ocupación en los sectores de comercio y servicios;

3. El marcado crecimiento del empleo por tiempo determinado y a jornada parcial;

4. El aumento del subcontratismo y de la maquila domiciliaria;

5. El incremento del empleo en relación de dependencia bajo nuevas condiciones contractuales. Este tipo de convenios rompe con dos de los principios que tradicionalmente habían servido de soportes al modelo contractual anterior: la estabilidad en el empleo y la permanencia del trabajador en puestos que eran relativamente similares en las funciones productivas que debían desarrollarse.

La combinatoria de estos factores y de otros elementos que hacen al funcionamiento del mercado laboral en el contexto de los nuevos criterios de la flexibilidad contractual, son responsables, en 
parte, de la mayor segmentación de los sectores asalariados de la población trabajadora, de la crisis de representación que afecta a las grandes centrales obreras y del debilitamiento progresivo de las bases sociales que fueron el sustento de los movimientos populistas de "viejo cuño" y de las fuerzas políticas de tradición marxista (trabajadores urbanos; empresarios vinculados al mercado interno; burocracia y sectores medios del comercio y los servicios (CAVAROZZI, 1996) ${ }^{2}$.

\section{Estado y democracia bajo la preeminencia del mercado}

Ambas esferas de la vida política, las instituciones públicas y los dispositivos del régimen parlamentario, han sido fuertemente sacudidos por la aplicación de los programas de reestructuración de las economías de la región. Una presentación un tanto esquemática del tema, nos permite sugerir que el debate acerca de estas dos instancias cruciales, puede organizarse de acuerdo a los postulados que sostienen tres concepciones principales:

1. Los principios del "viejo consenso"; este enfoque alude al paradigma que prevaleció en las ciencias sociales latinoamericanas desde los años 30 hasta mediados de la década de los 70. Este consenso - entendido como un bloque histórico que posibilitó la instauración de la estrategia de desarrollo basada en la industrialización protegida y en el mercado interno - le asignaba al Estado un papel predominante como factor de estímulo a las actividades productivas y como instancia de protección tutelar de la fuerza de trabajo. Michael Hansenne, director general de la Organización Internacional del Trabajo (OIT), explicó, de manera transparente, en su Informe Anual de 1992 a la Conferencia Regional Americana, que durante ese período, de algo más de cuatro décadas, definir políticas sobre cuestiones laborales era referirse a la preeminencia del Estado como regulador y garante de las metas de empleo, los sueldos

\footnotetext{
${ }^{2}$ Para un estudio de la crisis de los populismos latinoamericanos ver: Felipe Burbano
} de Lara (ed.). El fantasma del populismo. Caracas: ILDIS /Nueva Sociedad, 1998 
y las condiciones de trabajo; ello sin prestar gran atención al mercado y, en la mayoría de los casos, sólo con una participación simbólica de los actores sociales.

2. El enfoque neoliberal; desde este marco se afirma que el Estado debería intervenir lo menos posible para no interferir en el libre movimiento de las fuerzas del mercado. De acuerdo a esta perspectiva las organizaciones sociales y las instituciones y empresas públicas heredadas del antiguo "Estado desarrollista" son impedimentos, y de algún modo una amenaza, para alcanzar la modernización de la planta productiva. Un Estado y una sociedad menos protagónicos son el prerequisito para atraer inversiones y generar nuevas oportunidades de empleo.

3. La visión del "crecimiento con equidad"; el aumento de la pobreza, de la concentración del ingreso y la generalización del subempleo y la desocupación motivó que algunos organismos internacionales como la Comisión Económica para América Latina y el Caribe (CEPAL), revaloraran el papel de la intervención gubernamental en algunos espacios de la vida social, en particular en el ámbito del diseño e instrumentación de los programas de combate a la pobreza y en el mercado de trabajo. Aunque se redefine el rol que deben jugar las instancias públicas, se propone un accionar menos predominante para el Estado del que se le adjudicaba en el "viejo consenso". El principal punto de divergencia entre este enfoque y los dos anteriores reside en las funciones que se le atribuyen a las organizaciones sociales y a las diversas expresiones societales que pugnan por la gestión directa de los ciudadanos en la producción y distribución de ciertos bienes y servicios básicos. (CORTÁZAR, 1999).

Lo cierto es que desde inicios de los ochentas América Latina conoció, en carne propia, la implantación de políticas de ajuste, cuando la prioridad era disciplinar las variables macroeconómicas que se descontrolaron con la crisis de la deuda, y poco después, a mediados de esa misma década, la tenaz aplicación de programas económicos destinados a establecer un nuevo patrón de acumulación. Es importante señalar que el recetario de medidas económico-sociales que llegó a nuestros países tenía una cobertura ideológica ciudadosamente elaborada 
en los medios académicos de los países industrializados. En efecto, el paquete que se exportó a la región tenía dos novedades centrales. Una de ellas era el ensamble de los postulados neoliberales con "valores democráticos" de origen neoconservador. Cabe recordar que en el cuerpo doctrinario del liberalismo clásico las formas institucionales democráticas habían ocupado un lugar expresamente subordinado al instrumental de carácter propiamente económico (EZCURRA, 1998).

El proyecto neoconservador que llegó a Latinoamérica retomaba y vigorizaba la noción de "capitalismo democrático". Este es un vector clave, ya que forma parte del núcleo constitutivo de un nuevo consenso ideológico que postula la adhesión a la economía de libre mercado y a la democracia liberal y afirma la relación necesaria entre ambos principios. De esta manera, para las naciones del hemisferio Norte la "democratización global" ascendió a la categoría de cuestión de seguridad. En los 80, esta racionalidad comenzó a ser gradualmente impuesta en nuestros países, el patrocinio de la democracia parlamentaria en el subcontinente significó un vuelco de la visión conservadora tradicional hacia la idea de que las dictaduras de corte "pinochetista" representaban un escollo para el manejo de la cuestión social y para el establecimiento de un marco institucional que fijara nuevas reglas del juego.

La crisis de los regímenes dictatoriales, en particular en Sudamérica, coincidió con un marcado proceso de valorización de la institucionalidad democrática por parte de amplios sectores del espectro político. Esta oleada de recuperación del pluralismo y de las libertades ciudadanas incluyó a segmentos de la izquierda que habían renegado, durante los años 60 y 70, de las formas democráticas, de los procesos electorales y en general, de todos aquellos dispositivos asociados a la democracia parlamentaria. La misma izquierda que se apresuró a ahogar bajo las consignas atronadoras de la guerra popular y de la insurrección armada a los gobiernos surgidos de las elecciones que se efectuaron diez o quince años antes, propusieron en los 80 la instauración de un gobierno representativo. Y aquí cabe una aclaración, puede concebirse a la democracia como un método para la formulación y toma de decisiones en el ámbito estatal o bien imaginar la democracia como una forma de vida, como un modo cotidiano de relación entre hombres y mujeres mediante el cual se fijan reglas comunes para llevar a cabo el conjunto 
de actividades de una sociedad (NUN, 1990). Expresado de otro modo, es la diferencia que existe entre una democracia "gobernada" y una democracia "gobernante". En el primer caso la participación popular tiene reservado un papel secundario, de manera periódica, las leyes que norman los procesos electorales convocan a los ciudadanos para que decidan, mediante el voto universal, cual de las minorías potencialmente dirigentes debe asumir la responsabilidad de ejercer la administración de las instituciones públicas. Una vez cumplido este acto lo disuelve como "sujeto con identidad propia", el ciudadano pierde estatus como actor colectivo y el pueblo vuelve a sus tareas cotidianas.

Distinto es el caso de la democracia "gobernante" que procura abrir espacios y ampliar la participación ciudadana en la formulación y ejecución de las políticas públicas y en la toma de decisiones de todas aquellas cuestiones que atañen al conjunto de la sociedad. De acuerdo a los postulados de esta concepción, las instituciones democráticas sólo adquieren ese verdadero carácter cuando el pueblo participa en la identificación y solución de los asuntos que conciernen a la comunidad y no exclusivamente en la elección de quienes tendrán a su cargo el desempeño de las funciones públicas.

La normalización de la vida política en los países que dejaban atrás procesos dictatoriales, dio lugar a la instauración de gobiernos democráticos con características que se aproximan a la primera de las tipologías mencionadas. En efecto, la convocatoria a elecciones y el reestablecimiento de la actividad parlamentaria, volvió a otorgar centralidad a los partidos políticos y relegó el papel de las organizaciones sociales. La jerarquización de los mecanismos propios de la formalidad democrática redujo los espacios de participación popular que no se expresan bajo las formas convencionales de los partidos.

\section{La primacía de la cuestión local: protesta social y ebullición ciudadana}

Desde los años 30 el Estado fue percibido en nuestros países como el gran demiurgo de la historia, era el artífice del desarrollo industrial, de la modernización del campo y el garante del bienestar social para las 
clases populares. Fueron demasiadas esperanzas depositadas en una institución política. Casi 50 años después y en medio de una fuerte ofensiva neoconservadora, se puso en marcha un proceso de demolición de las antiguas estructuras públicas. Surgió entonces un nuevo tótem: el mercado. Se necesitaron poco más de 20 años para saber que este ídolo tenía pies de barro. Era preciso que golpeáramos la cabeza contra la pared para entender que el mercado sin controles destrozaba la convivencia democrática y volvía ficticias las libertades ciudadanas. Se produjo entonces una súbita adhesión al concepto de sociedad civil, categoría de larga prosapia que habían rehabilitado los disidentes de Europa del Este en los años 70 y que las corrientes conservadoras de la sociología estadounidense recibieron con beneplácito ${ }^{3}$.

Pero el llamado de alerta llegó un poco tarde, este retorno, intelectual y político al "reino ciudadano", se produjo cuando el daño ya estaba hecho. La mayor segmentación de los grupos y clases sociales que habían sido el soporte estructural y referente político fundante de las sociedades latinoamericanas, agotó también los horizontes simbólicos de las fuerzas políticas tradicionales. Esta crisis de representación, notoria a partir de la implantación de la estrategia neoliberal generó, por parte de segmentos importantes de la sociedad, primero indiferencia y después escepticismo, hacia los partidos históricos. Los que habían sido depositarios naturales de las expectativas populares se transformaron, a los ojos de la población, en fuente de corrupción y de promesas incumplidas.

La réplica a este proceso de descreimiento ha sido el surgimiento de liderazgos locales, más conocidos en sus municipios y comunidades y fuertemente ligados a los intereses inmediatos de sus vecinos. La experiencia argentina sirve para ilustrar este fenómeno de conformación de agrupamientos municipales que han logrado, en muchos casos, salir victoriosos en las elecciones para designar a los titulares de las comunas y a los integrantes de los consejos vecinales.

La emergencia de estas fuerzas de raíz municipal reconoce, en Argentina, algunos antecedentes valiosos de "autogestión popular".

\footnotetext{
${ }^{3}$ Puede consultarse el detallado estudio sobre los usos del concepto de sociedad civil en la sociología norteamericana en BARBER (2000).
} 
En 1981 se inició la ocupación ilegal de terrenos en la zona sur del conurbano de Buenos Aires, con estos hechos dio comienzo una nueva modalidad de producción del hábitat y de organización social de los sectores populares (MERKLEN, 1997). Estas ocupaciones ilegales de tierras se caracterizaron por ser masivas y por planificar el uso del suelo y el desarrollo futuro del barrio. A partir de criterios autogestionarios, cientos de familias se instalaban en los predios baldíos, trazaban los lotes y las calles con el fin de asignar un terreno a cada familia, dejar espacios libres para las áreas de uso colectivo, y construir la red eléctrica, las tuberías de agua potable, los centros de salud y guarderías. Si quisiéramos identificar el aspecto de mayor originalidad, en este tipo de experiencias, hay que apuntar el particular modo de vincularse con la ciudad que proponen estos nuevos asentamientos. Constituyen un intento de ser reconocidos por las autoridades y, al mismo tiempo, asimilarse al resto del núcleo urbano mediante una política de autoorganización y de hechos consumados (IZAGUIRRE; ARISTIZÁBAL, 1989). El agrupamiento de los pobladores - que en muchos casos fueron la base de las futuras asociaciones vecinales - se estructuraba a partir de tres instancias: Comisión Directiva, Comisiones Especiales y el Cuerpo de Delegados; los procedimientos para tomar decisiones eran la asamblea y la elección directa.

Es importante señalar un rasgo sustantivo en este tipo de organización autogestiva. Todos los grupos vecinales se construyeron sobre la idea de la autonomía respecto de la competencia político-partidaria. De esta forma los representantes de los vecinos se definían como "apartidarios" o "apolíticos". Esta conducta favoreció la unidad organizativa de los barrios, al colocar la competencia política fuera de sus límites y acotar las diferencias entre vecinos puertas adentro. Puede decirse que había un límite visible entre las organizaciones sociales, surgidas de demandas específicas de la sociedad civil, y el sistema político.

Las agrupaciones vecinales que surgieron durante los 80 y que se extendieron en los últimos diez años, muestran algunos cambios importantes con respecto a las experiencias que se acaban de mencionar. Se mantuvo cierto desdén y rechazo hacia las dirigencias políticas tradicionales pero, al mismo tiempo, se expresó un abierto interés por disputar electoralmente el control de las comunas (DI TELLA, 2001). La 
señal de identificación que exhiben las organizaciones vecinalistas sigue siendo el descreimiento común que sienten por las antiguas fuerzas políticas y todas coinciden es un aspecto que puede constituirse en un punto vulnerable: la heterogeneidad de los sectores de población que las conforman. Entre sus bases de apoyo es posible reconocer a trabajadores de la industria, burócratas y comerciantes, técnicos y profesionales, desempleados y subocupados o grupos marginales cuyo objetivo principal es obtener un lugar donde vivir. La composición ideológica de las bases sociales del movimiento "vecinalista" es variada, en ciertos casos se encuentran expresiones cercanas a corrientes políticas históricas como el peronismo y la Unión Cívica Radical, en otros parecen responder a fuerzas conservadoras de confusa procedencia, incluidos grupos que colaboraron con la dictadura militar. No obstante, las agrupaciones vecinales efectúan sus convocatorias con carácter amplio, sin discriminar por posturas ideológicas o antecedentes partidarios. El objetivo político central es jerarquizar el rol municipal, lograr una mayor autonomía de las comunas y procurar que las elecciones en las que se vota para designar a los presidentes municipales y asambleistas, se efectúen de manera separada de las provinciales o federales. Estas banderas, junto a la prédica machacona contra la corrupción y la inseguridad, constituyen el programa mínimo de la mayoría de estas organizaciones.

El vecinalismo abre un espacio de lucha para la persona desempleada que ya no cuenta con un sindicato al cual llevar sus demandas y lograr que lo defienda, y para los trabajadores precarios, los ocupados por cuenta propia, los subempleados y para aquellos que aún teniendo una inserción laboral estable no confían ni se sienten representados por las antiguas estructuras gremiales ni por las ofertas que provienen de los partidos políticos. Desde el Estado se hacen reiterados esfuerzos de cooptación. Durante la última dictadura que gobernó Argentina en el período 1976-83, se trató de armar lazos con la sociedad luego de los primeros años de terror. Vecinos "reconocidos" de las comunidades eran elegidos para reemplazar a los militares que administraban los municipios. En 1983, con el reestablecimiento de la democracia, algunos decidieron presentarse a elecciones, con este fin crearon sus expresiones vecinales organizadas políticamente. 
El núcleo a partir del cual suelen articular su discurso los movimientos vecinalistas es la exaltación de la figura "del buen vecino". Por lo general se trata del ciudadano atraído por los valores que encarnan una "cuidada y austera" administración de los recursos municipales y de la prestación adecuada de los servicios básicos que se esperan de un Estado mínimo (PAVÓN, 2001). El éxito electoral de los candidatos vecinalistas se explica, en buena medida, por ser receptores del voto ciudadano que desea expresar su rechazo a la política bajo sus formas conocidas. Se entiende que una manera de "despolitizar" el voto es apoyar a un candidato que se presenta como un "buen vecino", que se hace cargo de la gestión cotidiana de los problemas de su entorno.

Con palabras simples y sin rodeos, Alberto Groppi - uno de los numerosos jefes comunales surgidos del movimiento vecinalista define los postulados que inspiran a las organizaciones municipales: "El vecinalismo no tiene una ideología a nivel macro. Es ideología simple, un espíritu de servicio permanente por la gente que a uno lo rodea". Otro presidente municipal, Ricardo Ubieto, de la comuna de Tigre señala que "el corazón del problema está en que se ha roto la relación entre la gente y la política porque ésta ya no resuelve ninguna de las necesidades cotidianas de los sectores sociales[...] el vecinalismo es la soberanía del bache, de la luz eléctrica, ver como prestas mejores servicios y no meterte en los grandes problemas ya que no los vas a solucionar[...]" (TESTIMONIOS apud PAVÓN, 2001).

El auge del "vecinalismo", a mediados de los 80, coincidió con el surgimiento, y multiplicación de las redes solidarias. Un relevamiento, publicado en mayo del 2000, que efectuaron el Banco Interamericano de Desarrollo (BID) y el Programa de las Naciones Unidas para el Desarrollo (PNUD) muestra que hay más de 100 mil organizaciones comunitarias en Argentina (IGLESIAS, 2000). Se trata de entidades de bien público, sin fines de lucro, que se forman con el único propósito de defender las demandas ciudadanas. En el capítulo de conclusiones del documento Indice de Desarrollo de la Sociedad Civil de la Argentina, se menciona que estos agrupamientos, que nacen sin patrocinio estatal, duplican a las instituciones educativas y son hasta siete veces más numerosas que las de salud. 
En 1996 se creó el Foro del Sector Social con el fin de fomentar la participación ciudadana. En un material de difusión el Foro se pregunta: “¿Qué podemos hacer?”. Y el mismo texto propone: "Cuidar a un niño solo, cocinar para gente de la calle, acompañar a un discapacitado, leerle a un enfermo. Es que ser solidario no es sólo dar comida sino también dar una mano, ser respetuosos. La sociedad ya maduró. Ya no quiere ser más parte de ese Estado paternalista que se encargaba de todo, ahora la gente tiene iniciativas y.actúa ${ }^{4}$.

Otro fenómeno de especial relevancia es la aparición de mercados en los que se adquieren y venden diversos bienes y servicios mediante el sistema de trueque. Estos mercados iniciaron a mediados de los 90 , impulsados por miles de trabajadores desempleados y subocupados como un mecanismo alternativo al sistema formal de comercio. En apariencia, el sistema de trueque no se diferencia de un acto de compraventa rutinario, ya que cada artículo tiene un valor en "créditos". Pero estos billetes no son otra cosa que el valor del trabajo que cada persona aporta: no son intercambiables por dinero, tampoco reemplazan a la moneda corriente ni generan ningún interés. Carlos De Sanzo, uno de los fundadores de la Red Global del Trueque Solidario señala que: “[...] cualquier club de trueque está en condiciones de darle a un desocupado respuesta a cortísimo plazo: barrer o pintar o, quizá su esposa, atender a un enfermo o preparar comidas [...] el trueque funciona como interfase entre el mercado social y el mercado formal y opera en los intersticios de la economía: con las butacas que quedan vacías en el teatro, con las horas que quedan sin trabajar, con la mercadería que queda sin vender".

"El primer club de trueque se fundó en 1994. Hoy son más de 800 y hay 90 mil familias cuyo sustento depende total o parcialmente del trueque [...] sumando casi 500 mil personas" (LIPCOVICH, 2001).

Bajo la forma de asociaciones vecinales o mediante este curioso sistema de mercados autogestivos, la sociedad civil busca recomponer lazos de solidaridad que se perdieron con el debilitamiento de las anteriores formas de representación popular. En aquellos espacios donde los sindicatos ya no llegan - el incremento del desempleo, del trabajo

\footnotetext{
4 Palabras de los dirigentes del Foro del Sector Social citadas en el informe de Mariana Iglesias (2000).
} 
precario y de la ocupación domiciliaria le restaron bases sociales - y donde los partidos tradicionales dejaron de actuar como grandes agregarlos de la voluntad "nacionalista-popular", las demandas de la población son atendidas por instancias peculiares que genera la propia sociedad civil.

No obstante, las experiencias autogestionarias y vecinalistas abren múltiples interrogantes. Para la socióloga Maristella Svampa, responsable de la cátedra Simón Bolívar del Instituto de Altos Estudios de América Latina de la Sorbona, los riesgos que enfrentan estos movimientos sociales son muy altos. Svampa se pregunta "¿Puede la política convertirse en la sola gestión de los problemas cotidianos de la gente, ignorando las definiciones más generales, que están detrás de las decisiones de más largo plazo y que tienen que ver con la idea de sociedad que tenemos y queremos?" (LIPCOVICH apud PAVÓN, 2001). Esta marca identitaria de los representantes del movimiento vecinalista - estar alejados del juego político tradicional - puede transformarse en el árbol que oculte el bosque, al no advertir que la política es una tarea colectiva que se nutre del mundo de los valores y que implica opciones, ideologías y creencias.

Los riesgos que se señalan no descalifican las experiencias de "democracia directa" y autogestión que se describen en este artículo. El vecinalismo es un fenómeno que ha comenzado a crecer en América Latina, prácticas similares a las que se encuentran en Argentina se registran también en Paraguay, Chile, Brasil y Uruguay. Con elementos particulares, dictados por la rudeza del mundo campesino en el que nació, puede incluirse al movimiento de los "Sin Tierra" en Brasil, tal vez lo más logrado en cuanto al impulso de labores productivas y prestación solidaria de servicios educativos y de salud.

Es posible que estas nuevas estructuras no sustituyan a las antiguas y, por el contrario, se articulen con ellas. El desafío, que tendrán que resolver, será la dificultad de vinculación con formas políticas de mayor alcance, provincial o nacional, sin que se diluyan su especificidad y sus valores. En este afán de crecer - en Buenos Aires se constituyó el Frente Vecinal Provincial con el fin de competir en las elecciones legislativas del 2001 - se anida el riesgo de la fagocitación a partir de acuerdos que establezcan con fuerzas políticas nacionales. Renunciar 
a las tentaciones de la ideología parece un acto de afirmación de la pureza de las demandas ciudadanas. Sin embargo, puede significar el ingreso a un universo lúdico en el que se repliquen imágenes distorsionadas de la realidad social y de cuyos espejismos, sólo se logra salir por el camino de la política.

\section{Referencias Bibligráficas}

BARBER, Benjamín R. Un lugar para todos. Buenos Aires: Paidos, 2000.

CAVAROZZI, Marcelo. Populismos y partidos de clase media. Notas comparativas. In: VILAS, Carlos (Comp.). La democratización fundamental. El populismo en América Latina. México: Conaculta, 1996.

CORTÁZAR, René. Globalización y puestos de trabajo. Una perspectiva latinoamericana. In: TOKMAN, Víctor; O’DONNELL, Guillermo. (Comps.). Pobreza y desigualdad en América Latina. Temas y nuevos desafíos. Buenos Aires: Paidós, 1999.

DI TELLA, Torcuato. Los síntomas de cierta ebullición. Clarín, Buenos Aires, 22 abr. 2001.

EZCURRA, Ana María. ¿Qué es el neoliberalismo? Evolución y límites de un modelo excluyente. Buenos Aires: Lugar Editorial/IDEAS, 1998.

IGLESIAS, Mariana. Cada vez hay más redes solidarias en el país. Clarín, Buenos Aires, 26 ago. 2000.

IZAGUIRRE, Inés; ARISTIZÁBAL, Zulema. Las Tomas de tierras en la zona sur del Gran Buenos Aires. Un ejercicio de formación de poder en el campo popular: Buenos Aires: Centro Editor de América Latina, 1989.

LIPCOVICH, Pedro. El trueque, un fenómeno que crece con la depresión de la economía. Diario de la Union, Buenos Aires, 26 mar. 2001. p.12.

MERKLEN, Denis. Organización comunitaria y práctica política. Las ocupaciones de tierras en el conurbano de Buenos Aires. Nueva Sociedad. Caracas, n.149, p.162-177, mayo-junio, 1997.

NUN, José. La rebelión del coro. Estudios sobre la racionalidad política y el sentido común. Buenos Aires: Ediciones Nueva Visión, 1990. 
O'DONNELL, Guillermo. Pobreza y desigualdad en América Latina: algunas reflexiones políticas. In: TOKMAN, Víctor; O'DONNELL, Guillermo. (Comps.). Pobreza y desigualdad en América Latina. Temas y nuevos desafíos. Buenos Aires: Paidós, 1999.

PAVÓN, Héctor. Los partidos que vienen de los barrios. Clarín, Buenos Aires, 22 abr. 2001.

SOJO, Ana. La política social en la encrucijada: ¿opciones o disyuntivas? In: CARPIO, Jorge; NOVACOVSKI, Irene. (Comps.). De igual a igual. El desafío del Estado ante los nuevos problemas sociales. Buenos Aires: F.C.E./SIEMPRO, 1999.

\section{Abstract}

This article intends to question the fragility of the suburbs' social movements in view of the process of economic globalization under the liberalism terms. Its purpose is to show that the suburb's movements, for the localized and specified nature of its emergence and achievement, do not succeed in producing significant changes that could question the transformation processes in progress.

Key-words: suburbs social movements, globalization and liberalism

\section{Resumo}

$\mathrm{O}$ artigo busca pôr em questão a fragilidade dos movimentos sociais de bairros em face do processo de globalização econômica nos termos do liberalismo. Trata-se de demonstrar que os movimentos de bairro, pelo caráter localizado e particularizado de sua emergência e alcance não logram imprimir mudanças significativas que possam questionar os processos de transformações em curso.

Palavras-chave: movimentos sociais de bairro; globalização e liberalismo. 